\title{
Simulation of the Effect of Mould Parameters on the Thickness Changing in Deep Drawing Process
}

\author{
Guihua $\mathrm{Wu}^{1, \mathrm{a}}$, Shuai Chang ${ }^{2, \mathrm{~b}}$ \\ ${ }^{1}$ School of Mechanical and Power Engineering, Chongqing University of Science and Technology, \\ Chongqing 401331, China; \\ 2 School of Mechanical Engineering, Chongqing University, Chongqing, 400044, China.

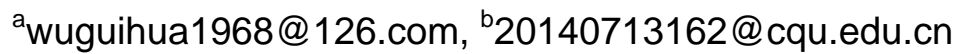

Keywords: Mould parameter, deep drawing, wall thickness, simulation analysis.

\begin{abstract}
As an aided tool of sheet metal forming process, the technology of computer simulation can reflect the interaction between the mould and blank dynamically, and the thickness distribution during the whole forming process. In the paper, the thickness attenuation ratio under different key mould parameters such as radius of die and punch, the gap between die and punch on the deep drawing process were analyzed. Detailed analysis shows that the thickness attenuation is smallest when radius of die is five times of wall thickness, radius of punch is four times of wall thickness, and the gap between die and punch is 1.02 times of wall thickness. The experiment indicates that computer simulation can be helpful for studying the connection between deep drawing process and mould parameters, and the results are beneficial of mould design and analysis of products quality.
\end{abstract}

\section{Introduction}

Deep drawing is one of the main methods in sheet metal forming process, which is widely used in producing thin-walled parts [1]. During the deep drawing process, there is a radial tensile stress and a circumferential compressive stress acting on the blank, thereby causing wall thickness changes, the thickest place is the opening part of the deep drawing part, while the thinnest wall thickness appears at the junction of deformed zone and punch fillet region, where fracture will be occurred when the radial tensile stress is greater than the tensile strength of forming material [2, 3]. There have many factors affect the wall thickness changing, such as material parameters, tool parameters and other processing parameters [4]. Material parameters can be obtained from materials manufacturer, and optimum process parameters such as blank holder force can be gained through trials-corrections, while optimum mould parameters obtained from trials-corrections is difficult due to its long cycle and high cost, and quantitative research the relationship between die parameters and wall thickness variation is very difficult. In recent year, the simulation analysis technology has been widely used in sheet metal forming process because of the rapid development of finite element method. The virtual mould can be used in simulation study on optimal parameters, which can not only save costs and also shorten manufacturing cycle, and a convenient method is provided to quantitative research on the various parameters and changes in thick-wall of the deep drawing parts [5, 6]. The work presented in the current paper is for analysis the relationship between mould parameters and the biggest wall thickness thinning rate.

\section{FE simulation of the deep drawing of thin-walled part}

Since the blank materials are anisotropic, anisotropic yield theory should be adopted to simulate the deep drawing process. The yield criterion proposed by Barlat and Lian in 1989 can reasonably describe the yield behavior, its expression is:

$$
\phi=\alpha\left|K_{1}+K_{2}\right|^{m}+\alpha\left|K_{1}-K_{2}\right|^{m}+(2-\alpha)\left|2 K_{2}\right|^{m}=2 \sigma_{s}{ }^{m}
$$

Where, $\sigma_{s}$ is yield stress and $K_{1}, K_{2}$ is given by: 


$$
\begin{aligned}
& K_{1}=\frac{\sigma_{x x}+h \sigma_{y y}}{2} \\
& K_{2}=\sqrt{\left(\frac{\sigma_{x x}-h \sigma_{y y}}{2}\right)^{2}+p^{2} \tau_{x y}^{2}} \\
& \alpha, c, h \text { and } p \text { are the anisotropic parameters of material, they can be expressed as: } \\
& \alpha=2-2 \sqrt{\frac{R_{0}}{1+R_{0}} \bullet \frac{R_{90}}{1+R_{90}}} \\
& h=\sqrt{\frac{R_{0}}{1+R_{0}} \cdot \frac{1+R_{90}}{R_{90}}} \\
& \frac{2 m \sigma_{s}^{m}}{\left(\frac{\partial \phi}{\partial \sigma_{x x}}+\frac{\partial \phi}{\partial \sigma_{y y}}\right) \bullet \sigma_{45}}-1-R_{45}=0
\end{aligned}
$$

Since aluminum alloy has cubic crystal structure, the yield function index $\mathrm{m}$ is 8 used in expression (1).

The commercial FEM code, DYNAFORM was employed to simulation the deep drawing process of sheet metal into circular cup. A 3D FE model was employed for the deep drawing simulation of a cup-shaped component as shown in Fig. 1. In this model, a 4-node shell element was utilized, and a surface-to-surface contact model between blank and tools (die, punch and blank holder) was adopted $[7,8]$, in which the coulomb friction law with a friction coefficient of 0.1 was concluded. The material is LF2-M with a thickness $2.5 \mathrm{~mm}$, the values of physical and mechanical properties of the blank material are shown in table 1 . Seven values of punch radii profile $\left(R_{p}=6,7,8,9,10,11\right.$ and $12 \mathrm{~mm})$, ten values of die radius profile $\left(\mathrm{R}_{\mathrm{d}}=5,7.5,8,9,10,11,12.5,14,15\right.$ and $\left.16 \mathrm{~mm}\right)$ and eight values of die clearance $(\mathrm{Z}=2.3,2.35,2.4,2.45,2.5,2.55,2.6$ and $2.7 \mathrm{~mm})$ are employed during this study to investigate their effects on variation in thickness of deep drawing part. While constant value of drawing speed $(\mathrm{V}=1000 \mathrm{~mm} / \mathrm{min})$, blank diameter $(\mathrm{BD}=150 \mathrm{~mm})$, punch diameter $\left(\mathrm{D}_{\mathrm{p}}=75 \mathrm{~mm}\right)$ and blank holder force $(\mathrm{BHF}=10000 \mathrm{~N})$ are used during the simulation. Elasto-plastic behavior for work material was used in the simulation. The solid element was used for the blank material. The tool set (die, punch and blank holder) was modeled as rigid body. Automatic contact procedure in DYNAFORM was employed to model the complex interaction between the blank and tools.

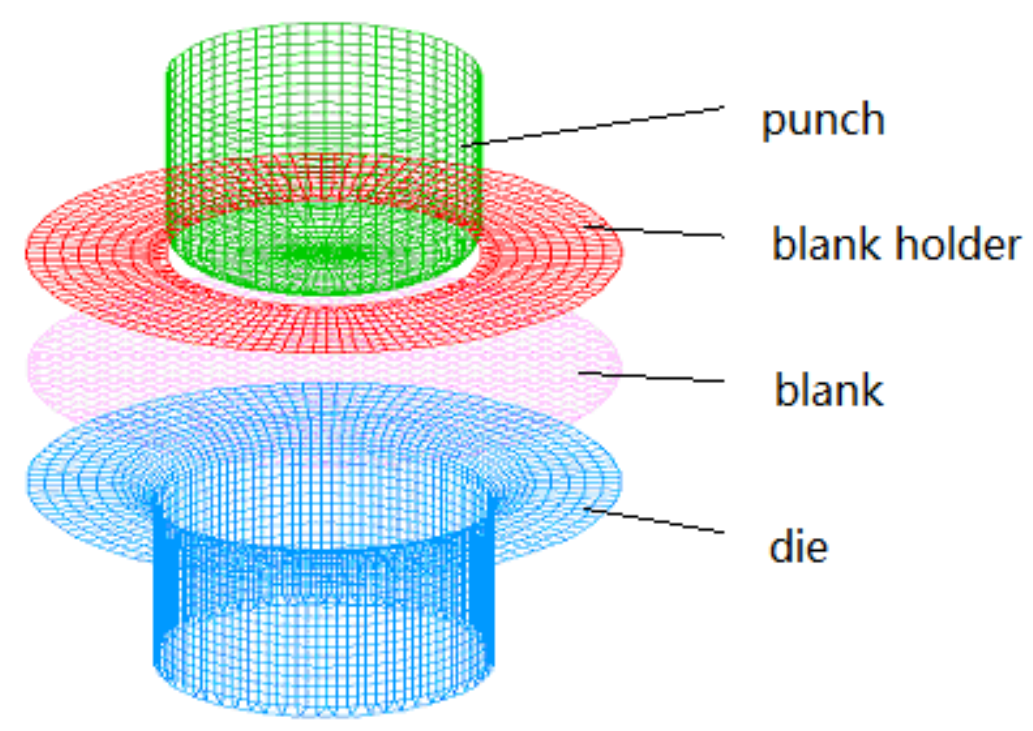

Fig. 1 FE model of circular deep drawing part 
Table 1 Values of the physical and mechanical properties of the blank material

\begin{tabular}{|c|c|c|c|c|c|c|c|}
\hline \multirow{2}{*}{$\begin{array}{c}\text { Density } \\
\rho\end{array}$} & \multirow{2}{*}{$\begin{array}{c}\text { Poisson's } \\
\text { ratio } \\
v\end{array}$} & \multirow{2}{*}{$\begin{array}{c}\text { Strength } \\
\text { coefficien } \\
\mathrm{t} \\
\mathrm{K}\end{array}$} & \multirow{2}{*}{$\begin{array}{c}\text { Elastic } \\
\text { modulus } \\
\text { E }\end{array}$} & \multirow{2}{*}{$\begin{array}{l}\text { Hardenin } \\
\text { g } \\
\text { exponent } \\
n\end{array}$} & \multicolumn{3}{|c|}{$\begin{array}{c}\text { Anisotropy coefficient } \\
\text { R }\end{array}$} \\
\hline & & & & & R0 & R45 & R90 \\
\hline $2.77 \mathrm{~g} / \mathrm{cm} 3$ & 0.31 & $185 \mathrm{MPa}$ & 73GPa & 0.198 & 0.364 & 0.833 & 0.49 \\
\hline
\end{tabular}

\section{Results and discussion}

Table 2 shows maximum thickness attenuation obtained from simulation different values of punch radii profile, while other parameters fixed.

It can be seen that, the maximum thickness thinning rate of the deep drawing part decreases with the increase in the punch radius. The variation of maximum thinning rate of deep drawing part is very small with increasing the punch radii profile when punch radius $\mathrm{Rd}$ is bigger than four times thickness of blank. While the variation of maximum thinning rate of deep drawing part increases dramatically with punch radius decreasing when punch radius Rd is smaller than four times thickness of blank.

Table 2 Relationship between punch radii profile and maximum thickness attenuation

\begin{tabular}{cccccccc}
\hline $\begin{array}{c}\text { punch radii profile } \\
\text { Rd(mm) }\end{array}$ & 6 & 7 & 8 & 9 & 10 & 11 & 12 \\
\hline $\begin{array}{c}\text { Maximum thickness } \\
\text { attenuation(\%) }\end{array}$ & 14.51 & 10.19 & 10.16 & 10.09 & 8.99 & 8.87 & 8.83 \\
\hline
\end{tabular}

Table 3 shows maximum thickness attenuation obtained from simulation different values of die clearance, while other parameters fixed.

Table 3 shows that the thinning rate of deep drawing part is gradually increased with the decrease of die clearance when the die clearance is less than the wall thickness of the work-piece. The reason is that when the mould gap is smaller than the blank thickness, the deformation resistance increases, which leads to increase the radical tensile stress of material on the punch corner place, therefore, the thinning rate increases, at the same time cracking tendency increases. The thinning rate increases with the increase of clearance when mould clearance is greater than the work-piece thickness. The minimum value of maximum thinning rate is occurred at the die clearance equaling to 1.02 times of wall thickness.

Table 3 Relationship between die clearance and maximum thickness attenuation

\begin{tabular}{ccccccccc}
\hline die clearance (mm) & 2.3 & 2.35 & 2.4 & 2.45 & 2.5 & 2.55 & 2.6 & 2.7 \\
\hline $\begin{array}{c}\text { Maximum thickness } \\
\text { attenuation(\%) }\end{array}$ & 9.27 & 9.20 & 9.18 & 9.04 & 9.00 & 8.99 & 9.20 & 9.22 \\
\hline
\end{tabular}

Table 4 shows maximum thickness attenuation obtained from simulation different values of die radius profile, while other parameters fixed.

The thinning rate is decrease gradually with the increase of die radius, when the die fillet radius is smaller than five times of wall thickness, and the variability of the thinning rate is large. The wall thickness produces only modest changes with the increase of die fillet radius, when the value of die radius is greater than five times of wall thickness.

Table 4 Relationship between die radii profile and maximum thickness attenuation

\begin{tabular}{ccccccccccc}
\hline $\begin{array}{c}\text { die radii profile } \\
\text { Rp (mm) }\end{array}$ & 5 & 7.5 & 8 & 9 & 10 & 11 & 12.5 & 14 & 15 & 16 \\
\hline $\begin{array}{c}\text { Maximum } \\
\text { thickness } \\
\text { attenuation(\%) }\end{array}$ & 15.31 & 13.64 & 12.65 & 11.52 & 10.42 & 9.35 & 8.99 & 8.78 & 8.65 & 8.65 \\
\hline
\end{tabular}




\section{Conclusion}

There has little changes occurred at the punch radii material maximum thickness attenuation with the increase of value of punch radii profile Rp when Rp is greater than four times of wall thickness. While wall thickness at punch radius is sharply thinning with punch radius value decreasing when punch radius $\mathrm{Rp}$ is smaller than three times thickness of blank.

The maximum thickness thinning rate decreases gradually with the increase of concave die radius when the die radii profile Rd is smaller than five times thickness of blank. However, little wall thickness variation occurs with the increase of die radius $\mathrm{Rd}$ when $\mathrm{Rd}$ is five times greater than thickness of blank.

There has little effect on the maximum thickness attenuation when the value of die clearance is close to blank thickness. The wall thickness thinning rate is smallest when the gap between die and punch is 1.02 times of blank thickness.

In mould parameters, the influence sequence which effects wall thickness thinning rate of deep drawing part is punch radii profile $\mathrm{Rp}>$ die fillet radius $\mathrm{Rd}>$ die clearance.

Generally, in order to get better quality of deep drawing parts, the die fillet radius Rd is five times of blank thickness, the punch radii profile $\mathrm{Rd}$ is four times of blank thickness, and the die clearance is 1.02 times of blank thickness.

\section{Acknowledgements}

This work was financially supported by the Scientific and Technological Research Program of Chongqing Municipal Education Commission (KJ121422).

\section{References}

[1] K. Debray. Y. M. Li. Y.Q. Guo. Int J Mater Form 6 (2013), p.315-325.

[2] Jansson T. Nilsson L. Struct Multidisc Optim. Vol. 31(2006), p. 320-332.

[3] Junchao Li. Jianbiao Hu. Junjie Pan et al. Int J Adv Manuf Technol. Vol. 62(2012), p.981-988.

[4] A. Anil Kumar. Satyanarayan Satapathy. D. Ravi Kumar. Journal of materials engineering and performance. Vol. 19(2010), p. 1150-1160.

[5] Gao Enzhi, Li Hongwei, Kou hongchao et al. Rare metals. Vol.29(2010), p. 108-113.

[6] Sartip Latif Hussein, Wael Ali Khudhair. International Journal of Arts \& Sciences. 4(2011), p. 143-159.

[7] Jinyan wang. Jixian Sun. Int J Mech Mater Des. 8(2012), p. 327-333.

[8] A. Qattawi. Ahnad mayyas. H. Thiruvengadam et al. J Intell Manuf. 25(2014), p.109-128. 